\title{
Contrast Enhanced PET-CT Scan
}

National Cancer Institute

\section{Source}

National Cancer Institute. Contrast Enhanced PET-CT Scan. NCI Thesaurus. Code

C142335.

A form of PET/CT imaging in which radiopharmaceuticals is either ing ested or injected intravenously in an attempt to enhance the collected images for diagnostic purposes. 